\title{
Design of Real Time Weather Season Based on the Internet of Things
}

\author{
Wan Alamsyah, Eka Mutia, Yulina Ismida \\ Department of Civil, Faculty of Engineering \\ Universitas Samudra \\ Kota Langsa, Indonesia
}

\begin{abstract}
A study has been successfully conducted entitled the design of early detection of floods based on the Internet of Things. The purpose of this study was to design and build a prototype of an Internet of Things-based flood detection system, and to understand the processes and workings of IoT-based flood detection tools. The methods carried out in this study are hardware design used here, namely ultrasonic sensor HC-SR04 and software design used here Arduino IDE, XAMPP, and Notepadd++. In measuring the accuracy of the distance of objects with sensors, calibration tools are performed to obtain error results. After processing the error result obtained precision with a value of 0.99997 with a correlation determination value of R2 $=1$. After obtaining the results of the sensor calibration conducted web server testing, the water level output displayed by the browser as expected and running properly.
\end{abstract}

Keywords-weather, Internet of Things, PHP and Mys $Q L$

\section{INTRODUCTION}

Wheather is a phenomenon that exists at a certain time and in specific places for a very short period, such as in the morning, afternoon, or evening, and can vary depending on the time and place [1]. Weather patterns that change quickly make the population less receptive to the effects they have. Air temperature, air pressure, wind, and rainfall are all factors that influence the weather [2]. Flooding is a form of natural disaster that occurs frequently in tropical areas. When excessive water flows submerge the ground, it is called a flood [3]. Flooding occurs when the amount of water in a body of water, such as a river or lake, exceeds its normal limits, or when a dam breaks, allowing water to overflow. The absorption of rainwater to the ground has been decreased as a result of the construction of buildings, homes, and roads [4]. Floods occur regularly in different parts of Indonesia, posing a danger to the population in the form of property damage and casualties. As a consequence, we need data that can notify you automatically, conveniently, rapidly, anywhere, and at any time [5].

The Internet of Things (IoT) effectively links all devices to the internet, the Internet of Things is a philosophy that aims to extend the benefits of connectivity internet-connected continuously [6], and the Internet of Things is a concept that

\author{
Adawiyah, Rachmad Almi Putra*, Ida Ratna Nila \\ Department of Physics, Faculty of Teaching and Education \\ Universitas Samudra \\ Kota Langsa, Indonesia \\ *rachmad almi@unsam.ac.id
}

aims to expand the benefits of connectivity internet-connected continuously. In terms of capabilities including data sharing, remote control, and so on, including real-world objects [7].

Many previous researchers have investigated the use of an Internet of Things-based flood detection system, such as the issue of developing an Internet of Things-based flood detection system [8]. This research aims to monitor water levels online as soon as flooding information becomes accessible. This monitoring system employs Internet of Things technology to provide real-time level information. The BLYNK application uses water level sensors as data readers and NodeMCU ESP8266 as processors to send data wirelessly to Android smartphones.

Implementing a real-time framework for flood prediction based on ESP8266 and weather Application Programming Interface was the subject of research by Mahardika et al. [9]. This means that the early flood warning system uses the Weather application programming interface, the HC-SR04 sensor, the FC-37 module (rain sensor), and the YF-S201 sensor or flow sensor that is mounted on a water source, with the FC-37 and YF-S201 test results having a 0\% error percentage.

This tool can track for 24 hours and store a maximum of 65535 data, according to research conducted by Saleh et al. [10]. It is based on the Basic Stamp-2 microcontroller and uses a memory stick as data storage. There is a comparison between manually measuring and using instruments in this test, with a maximum error of $34 \%$ and a minimum precision of 92.01 percent.

Based on the findings of the previous studies, there is a need for a new study on the Design of Real-Time Weather Season Based Internet of Things. The NodeMCU microcontroller was used in this analysis, as well as the HCSR04 sensor and the Internet of Things (IoT) device, which can be accessed in real-time (Open Source). 


\section{METHODS}

The hardware and software design processes are used to create Internet of Things (IoT)-based systems. The device is being developed as a prototype (miniature).

The flowchart of the system to be installed is defined first, followed by the identification of the necessary system in the form of sensors, indicators, and a microcontroller connected to the server through the internet network with a WIFI module. It is implemented on the necessary hardware devices based on this design.

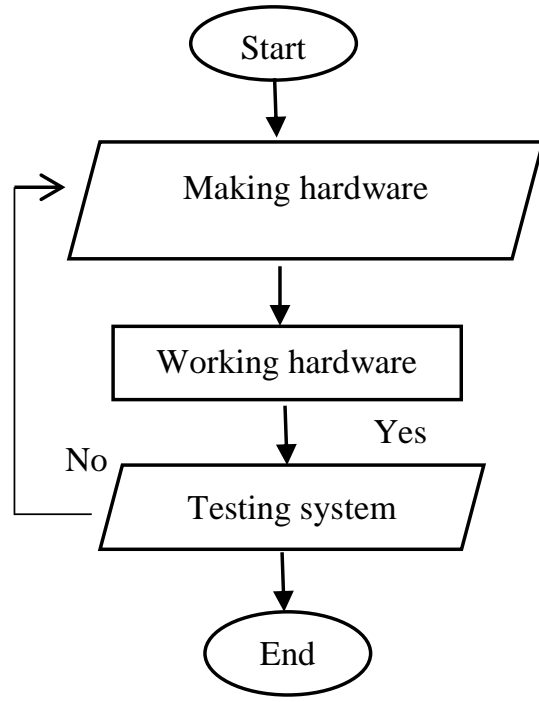

Fig. 1. Hardware production flowchart.

A NodeMCU with WiFiESP8266 and many sensors make up the hardware. The HCSR04 sensor, as well as a rain sensor and a wind sensor, are used in this equipment. Ultrasonic is a type of sensor that works by transmitting a wave and then measuring the time it takes for the wave to return to the sensor. The figure depicts the hardware design schematic.
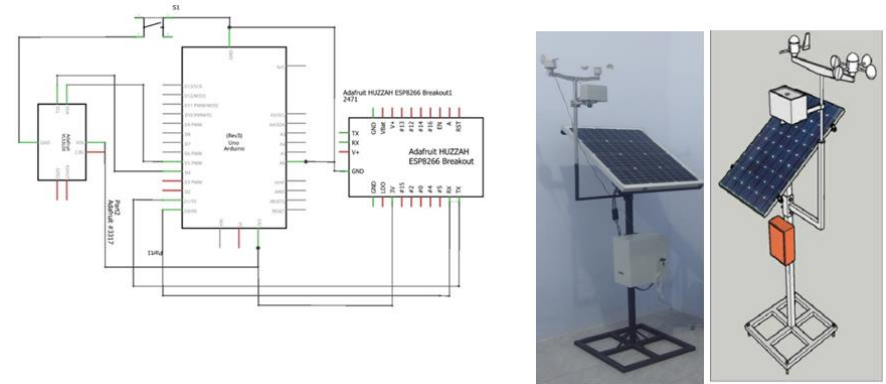

Fig. 2. a) Hardware Schematic, b) The Internet of Things (IoT) method for detecting weather.

The rain sensor and the wind sensor are attached to NodeMCU at predetermined pins in the hardware circuit. The HCSR04 sensor is attached to the Arduino board.
With the Internet of Things (IoT) approach to the consumer, software design is needed to program a microcontroller that can read and send server data.

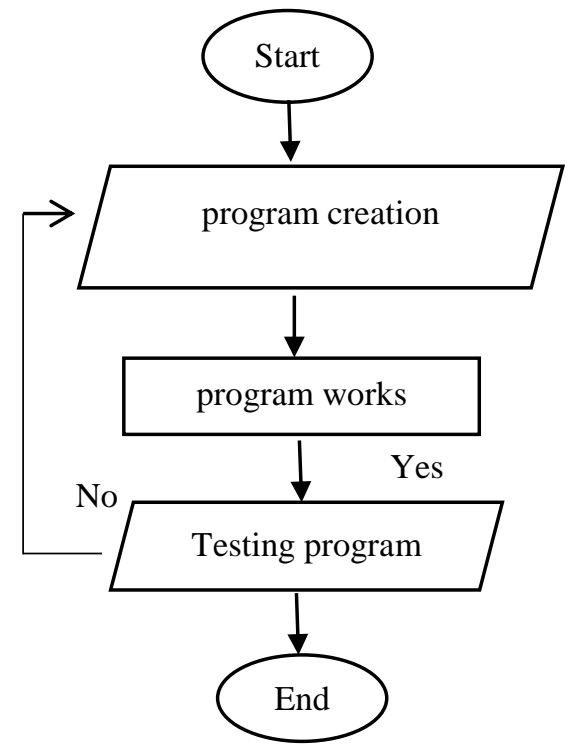

Fig. 3. Software development flowchart.

The programming language used in this stage is $\mathrm{C}$, which is uploaded to the microcontroller board using the Arduino IDE software, as well as Html as a website page. The data from the rain sensor input and the wind sensor is stored in a MySQL database and accessed via PHP MyAdmin. This database will house all of the system's information.

\section{RESULTS AND DISCUSSION}

\section{A. Sensor Calibration with the Ultrasonik HC-SRO4}

The sensor used in making a digital measuring instrument is still a relatively low voltage value, so the value does not represent the actual measured value. Several measurement procedures, including tool testing, are carried out in the framework of automated measuring instruments (tool calibration).

An Arduino program was written using the Arduino.ide software to read the measurement results of the HC-SR04 ultrasonic sensor. Knowing which pins the machine can use is the first step in creating an Arduino program. With this app, you can see the sensor readings shown on the serial monitor screen and use the initialization functions to configure the pins that will be used. The next step is to process the data or calibrate the distance measurement data to the expected value after receiving measurement readings from the HC-SR04 ultrasonic sensor.

The measurement results made by the sensor during the calibration of the HC-SR04 Ultrasonic sensor test tool are 10 measurements. Where linear regression method equations are used in the calculation, the linear regression formula, 
correlation coefficient $\mathrm{R}^{2}$, and graphs can be obtained using Microsoft Excel.

TABLE I. MEASUREMENT DATA $10 \mathrm{CM}-200 \mathrm{CM}$

\begin{tabular}{|c|c|c|c|c|c|c|c|c|}
\hline No & Xmanual & Ysensor & Zdigital & $\mathrm{X}^{\wedge} 2$ & $\mathrm{Y}^{\wedge} 2$ & X.Y & $\mathbf{X}(\mathbf{c m})$ & $\mathrm{Y}(\mathrm{cm})$ \\
\hline 1 & 10 & 102 & 6204 & 100 & 10404 & 1020 & 10 & 10.2 \\
\hline 2 & 20 & 204 & 12252 & 400 & 41616 & 4080 & 20 & 20.4 \\
\hline 3 & 30 & 305 & 17938 & 900 & 93025 & 9150 & 30 & 30.5 \\
\hline 4 & 40 & 399 & 23297 & 1600 & 159201 & 15960 & 40 & 39.9 \\
\hline 5 & 50 & 500 & 29319 & 2500 & 250000 & 25000 & 50 & 50 \\
\hline 6 & 60 & 599 & 34836 & 3600 & 358801 & 35940 & 60 & 59.9 \\
\hline 7 & 70 & 704 & 41069 & 4900 & 495616 & 49280 & 70 & 70.4 \\
\hline 8 & 80 & 798 & 46435 & 6400 & 636804 & 63840 & 80 & 79.8 \\
\hline 9 & 90 & 894 & 52230 & 8100 & 799236 & 80460 & 90 & 89.4 \\
\hline 10 & 100 & 996 & 58036 & 10000 & 992016 & 99600 & 100 & 99.6 \\
\hline 11 & 110 & 1092 & 63599 & 12100 & 1192464 & 120120 & 110 & 109.2 \\
\hline 12 & 120 & 1195 & 69490 & 14400 & 1428025 & 143400 & 120 & 119.5 \\
\hline 13 & 130 & 1297 & 75419 & 16900 & 1682209 & 168610 & 130 & 129.7 \\
\hline 14 & 140 & 1394 & 82033 & 19600 & 1943236 & 195160 & 140 & 139.4 \\
\hline 15 & 150 & 1495 & 86903 & 22500 & 2235025 & 224250 & 150 & 149.5 \\
\hline 16 & 160 & 1591 & 92470 & 25600 & 2531281 & 254560 & 160 & 159.1 \\
\hline 17 & 170 & 1698 & 98724 & 28900 & 2883204 & 288660 & 170 & 169.8 \\
\hline 18 & 180 & 1795 & 104417 & 32400 & 3222025 & 323100 & 180 & 179.5 \\
\hline 19 & 190 & 1895 & 110128 & 36100 & 3591025 & 360050 & 190 & 189.5 \\
\hline 20 & 200 & 1996 & 220001 & 40000 & 3984016 & 399200 & 200 & 199.6 \\
\hline Total & $\sum x=210$ & $\sum y=209$ & $\sum \Xi=13248$ & $\sum x^{2}=2870$ & $\sum y^{2}=285292$ & $\sum x y=28614$ & $\sum x=21$ & $\sum y=2094.9$ \\
\hline
\end{tabular}

We can get the linear regression formula, $\mathrm{R}^{2}$ correlation coefficient, and graphs using Microsoft Excel. The values an and $\mathrm{b}$ in the equation can be obtained using a linear regression method.

$$
\begin{gathered}
\mathrm{a}=\frac{\left[\sum X Y \cdot n-\sum X \cdot \sum Y\right]}{\left[\sum x^{2} \cdot n-\left[\sum x\right)^{2}\right]}, \\
\mathrm{b}=\frac{\left[\sum X Y n-\sum X \cdot \sum Y\right]}{\left[\sum x^{2} \cdot n-\left[\sum x\right)^{2}\right]}
\end{gathered}
$$

Error $=\frac{\left[\sum X Y n-\sum X \cdot \sum Y\right]}{\left[\sum x^{2} \cdot n-\left(\sum x\right)^{2}\right]} \sum x y-\frac{\sum X \sum Y}{n}=\sqrt{\left[\sum x^{2}-\frac{\left(\sum x\right)^{2}}{n}\right]\left[\sum y^{2}-\frac{\left(\sum y\right)^{2}}{n}\right]}$

Where $\mathrm{X}$ is the sensor-measured distance and $\mathrm{Y}$ is the manual-measured distance.

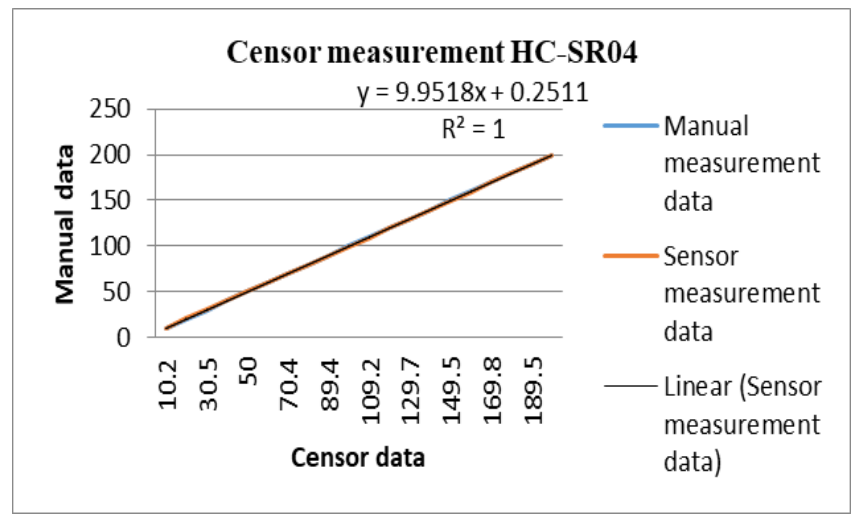

Fig. 4. Ratio calculation graph.
Figure 4 illustrates a close relationship between the measured (sensor) and manual measurement distances (ruler). When a distance is measured with an ultrasonic sensor, the temperature of the atmosphere surrounding the measurement is greatly affected. The measurement results on the graph, it can be inferred, indicate precision. Since the measurement results have a coefficient of determination of linear correlation between standard equipment and measurement results of $\mathrm{R}^{2}$, the precision of the measurement results can be as high as $200 \mathrm{~cm}$.

\section{B. Monitoring System}

The monitoring system serves as a data provider, and the data is analyzed after it is sent from the monitoring system. The MySql database is included as a DBMS (Database Management System), which is useful software for handling data in a versatile and timely manner. The MySQL database was chosen because it has many advantages over other databases, one of which is that it is open source software.

Figures 5-7 show the water level database, wind speed, and rainfall data, which will be displayed in real-time at localhost. 


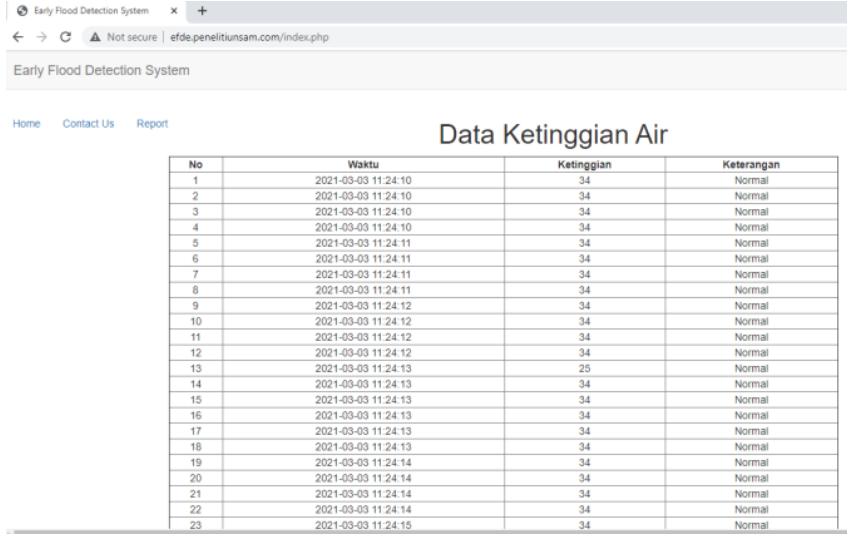

Fig. 5. On the internet, you can see a database of water levels.

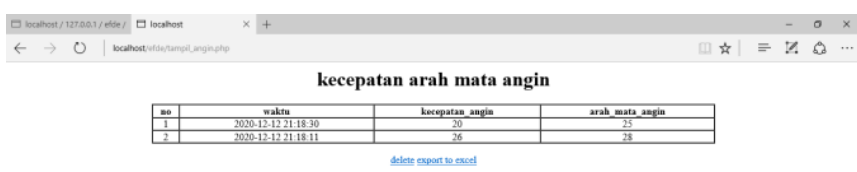

(1) 由

Fig. 6. On the internet, you can see a database of wind speeds.

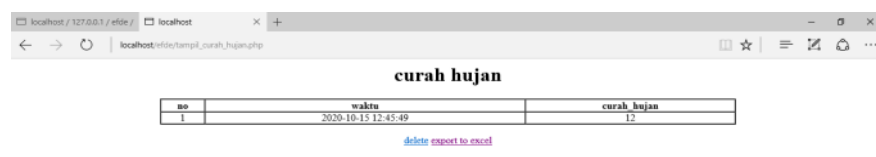

* 0

Fig. 7. On-line display of a rainfall database.

When the internet network is connected, the data will appear on the web and will have a huge effect on the network. The data cannot be viewed on the site while the network is down.

Various factors, such as air humidity and temperature, affect certain factors, such as temperature and humidity. The output of the flood detection system is also affected by temperature and humidity, resulting in the server link being blocked. When the sensor responds correctly, the data is saved to the database using the server, which is PHP and MySql in this case.

\section{CONCLUSION}

The development of a flood detection tool based on the internet of things, with hardware and software components. An ultrasonic sensor is attached to the WiFi module NodeMCU esp8266, as well as a buzzer, in the hardware design. Creating applications that allow you to program in XAMPP and Notepad++.

\section{ACKNOWLEDGMENT}

The authors express their gratitude to Universitas Samudra for funding the 2020 research program for young lecturers under contract number 560/UN54.6/PG/2020.

\section{REFERENCES}

[1] C. Hasiholan, R. Primananda, and K. Amron, "Implementation of the Concept of Internet of Things in the Flood Monitoring System using the MQTT Protocol," Pengemb. Technol. Inf. and Computer Science., vol. 2, no. 12, pp. 6128-6135, 2018.

[2] M.N.A.M. David Setiadi, "Application of the Internet of Things (IoT) on Irrigation Monitoring Systems (Smart Irrigation)," vol. 3, no. 2, 2018

[3] S.A. Bando, D. Darlis, and S. Aulia, "Implementation of Flood Early Detection Devices in Permata Buah Batu Housing with Internet of Things (IoT) Technology," e-Proceeding Appl. Sci., Vol. 2, no. 3, pp. 1376-1383, 2016

[4] J.B. Mallisetty, "Internet of Things Based Real Time Flood Monitoring and Alert Management system," vol. 118, no. 17, pp. 859-868, 2018

[5] N.L. Mufidah, "Website-Based Rainfall Information System with NodeMCU," vol. 1, pp. 25-34, 2018.

[6] N.V.S.S. Varma, E.E. Preethi, M.R. Kumar, and R.K. Tenali, "Internet of Things Based Smart Flood Monitoring \& Detecting System," vol. 7, no. 6, pp. 1335-1337, 2019.

[7] J.W. Simatupang and F. Naufal, "Flood Early Warning Detection System Prototype Based on IoT Network," vol. 11, no. 1, pp. 17-22, 2019.

[8] A. Muzakky, A. Nurhadi, A. Nurdiansyah, and G. Wicaksana, "Design of IoT-Based Flood Detection Systems," no. September, pp. 660-667, 2018.

[9] S.S. Mahardika, W. Kurniawan, and F.A. Bakhtiar, "Implementation of a Real Time System for Early Flood Detection based on ESP8266 and Weather API," vol. 3, no. 8, pp. 8238-8247, 2019

[10] K. Saleh, Fauziyah, Hadi, and Freddy, "Water Level Monitoring System Based on Basic Stamp-2 Microcontroller Using Memory Stick as Data Storage," Pros. Semirata FMIPA Univ. Lampung, pp. 511-515, 2013. 